Article

\title{
Investigation of the $H \beta$ Molecular Sieve Inactivation Caused by Reactants and Products and Improvement of Continuous Thiophene Acylation
}

\author{
Shunjin Yang ${ }^{1}$ and Aiwu Zeng ${ }^{1,2, *}$ \\ 1 State Key Laboratory of Chemical Engineering, School of Chemical Engineering and Technology, \\ Tianjin University, Tianjin 300350, China; 2018207533@tju.edu.cn \\ 2 Chemical Engineering Research Center, Collaborative Innovative Center of Chemical Science and \\ Engineering, Tianjin 300350, China \\ * Correspondence: awzeng@tju.edu.cn; Tel.: +86-139-2040-4701
}

Citation: Yang, S.; Zeng, A. Investigation of the $\mathrm{H} \beta$ Molecular Sieve Inactivation Caused by Reactants and Products and Improvement of Continuous Thiophene Acylation. Catalysts 2021, 11, 298. https://doi.org/10.3390/ catal11030298

Academic Editor: Benoît Louis

Received: 24 January 2021

Accepted: 18 February 2021

Published: 25 February 2021

Publisher's Note: MDPI stays neutral with regard to jurisdictional claims in published maps and institutional affiliations.

Copyright: (c) 2021 by the authors. Licensee MDPI, Basel, Switzerland. This article is an open access article distributed under the terms and conditions of the Creative Commons Attribution (CC BY) license (https:/ / creativecommons.org/licenses/by/ $4.0 /)$.

\begin{abstract}
In this paper, the factors leading to the inactivation of the molecular sieve are explored in the batch thiophene (TH) acylation. The coexistence of acetic anhydride (AC) as the reactant and 2-acetylthiophene (2-ATH) as the product plays a key role in accelerating the inactivation, attributing to the 2-ATH polymerization. According to the molecular simulation, when AC is not present, the energy barrier of 2-ATH polymerization can be reduced from $287.45 \mathrm{~kJ} / \mathrm{mol}$ to $85.87 \mathrm{~kJ} / \mathrm{mol}$. Then, the process of the continuous TH acylation is improved, in which thiophene is excessive (molar ratio). After optimizing the molar ratio and volume flowrate of raw material, the productivity of the catalyst can reach $21.56 \mathrm{~g} / \mathrm{g}$, which exceeds the best process previously studied $(15.10 \mathrm{~g} / \mathrm{g})$. Subsequently, the use of carbon tetrachloride (CT) as a solvent is further studied, hoping to further improve the performance of the catalyst, and a significant advancement is achieved, in which the production capacity of the catalyst exceeds $45 \mathrm{~g}$, and the conversion rate of AC can still be as high as $96 \%$ after the reaction is carried out for $15,000 \mathrm{~min}$.
\end{abstract}

Keywords: thiophene; 2-acetylthiophene; continuous reaction; $\mathrm{H} \beta$ molecular sieve

\section{Introduction}

The Friedel-Crafts (F-C) acylation reaction is an important method to synthesize aromatic ketone, which can serve as intermediates of various valuable chemical products [1-6]. However, in production under existing methods there are often some problems, such as the disposal of spent catalyst, corrosion to equipment, and environment and product purification [1,7]. Therefore, the development of clean and environmentally friendly catalysts for various F-C acylation reactions has become a research hotspot [8,9].

Nowadays, many new catalysts (such as zeolite molecular sieves and heteropolyacid (HPA)) are being researched to improve F-C acylation. HPA is promising, but it has some disadvantages, such as poor thermal stability, small specific surface area, and difficulty in catalyst regeneration, which reduce its prospects as an industrial catalyst. In response to the above problems, researchers proposed methods for HPA immobilization and the preparation of HPA salts. Phosphotungstic acid (HPW) can be supported on various supports (such as metal-organic frameworks [10,11] and montmorillonite [12]) to realize an acylation reaction with conversion rates over $90 \%$. Zeolite molecular sieves are also widely used in acylation reactions. They have the advantages of uniform pore distribution, good selectivity, easy separation from the product, good reproducibility and environmental friendliness. In various types of zeolite molecular sieves, the H-beta $(\mathrm{H} \beta)$ zeolite molecular sieve has wide applications. It can be used in an F-C acylation reaction of 2-methylnaphthalene [13], toluene [14], phenol [15], Parabens [16] and Anisole [17-19]. However, the above-mentioned reactions were generally carried out in batch. Even if the 
catalyst can be reused several times, it is still difficult to meet the continuous and stable production pursued in the industry.

Compared with a batch reaction, a continuous reaction has many advantages. First of all, a continuous reaction can greatly reduce the reactor volume, and the reactor can be infinitely enlarged with a stable product purity. Second, its operation is convenient, and there is no need to filter or use other methods to achieve the separation of product and catalyst. Third, because the product is continuously removed from the reactor, the concentration difference between the catalyst pores and the liquid main body can be increased; therefore, desorption of the product can be accelerated, and the occurrence of carbon deposits caused by the product can be suppressed. Therefore, the realization of a continuous acylation reaction is a very meaningful work.

The acylation of thiophene (TH) is relatively mild and can be achieved at $80{ }^{\circ} \mathrm{C}$ by using zeolite molecular sieves [20]. The product (2-acetylthiophene, 2-ATH) is also an important pharmaceutical intermediate, which can be used to synthesize duloxetine hydrochloride [21], indiplon [22] and so on. Therefore, the continuous acylation of TH is chosen to study in order to obtain a longer catalyst lifetime. Feng et al. [23] synthesized a $\mathrm{C}_{25}$ zeolite molecular sieve, which can be used in the continuous reaction. Before use, it needed to be pressed into a cylindrical shape. When the molar ratio $(\mathrm{TH} /$ acetic anhydride $(\mathrm{AC})$ ) of raw material was $1: 3$, the productivity and lifetime of the catalyst were $8.73 \mathrm{~g} / \mathrm{g}$ and $2630 \mathrm{~min}$, respectively. Further, the influence of by-product acetic acid (AA) was explored. When TH:AC:AA $=1: 2: 1$, the productivity of the catalyst can arrive at $15.10 \mathrm{~g} / \mathrm{g}$ with a reaction temperature of $70^{\circ} \mathrm{C}$. Chen et al. [24] explored the effect of an acid-modified $\mathrm{H} \beta$ molecular sieve on catalyst productivity in the continuous acylation of thiophene. When the reaction temperature and molar ratio were $80^{\circ} \mathrm{C}$ and $1: 2$, respectively, the treated capacity could arrive at $21.4 \mathrm{~g} / \mathrm{g}(\mathrm{AC}-\mathrm{H} \beta), 39.1 \mathrm{~g} / \mathrm{g}(\mathrm{HCl}-\mathrm{H} \beta)$ and $43.1 \mathrm{~g} / \mathrm{g}\left(\mathrm{HNO}_{3}-\mathrm{H} \beta\right)$. The increase in the catalytic ability can be attributed to the dealumination in the pores of the molecular sieve, which increased the diameter of the pore and exposed more active sites [25]. However, during several reaction-regeneration cycles, the treated capacity of the catalyst gradually decreased. Furan [26] and 2-methylfuran [27] were also investigated, taking the $\mathrm{H} \beta$ as the catalyst. The above-mentioned continuous reactions all have the universal problem of insufficient catalyst lifetime, but it is very important to find suitable methods to extend the catalyst lifetime in continuous reactions.

In this paper, the Gaussian 09W is used for molecular simulation [28]. Molecular simulation is used to infer the mechanism of catalyst inactivation and to calculate the dipole moment of related molecules to qualitatively determine the magnitude of its polarity. The interaction between molecules has a very important influence on the molecular contact and the determination of the whole reaction mechanism [29]. The molecular structure involved in this paper is simple and small, and the magnitude of the dipole moment can qualitatively reflect that of its polarity. The greater the polarity, the more likely it is to adsorb in the pores of the catalyst.

The main contribution of this paper was to investigate the influence of the four components (TH, AA, AC and 2-ATH) in the reaction system on the inactivation of an $\mathrm{H} \beta$ molecular sieve by soaking it in each component. In addition, molecular simulation (Gaussian 09W), as an auxiliary tool, was also applied to the research. According to the results, the continuous experiment of TH acylation was redesigned. Finally, the influence of solvents on the continuous thiophene acylation was explored and a suitable solvent was found to extend the lifetime and productivity of the catalyst greatly.

\section{The Mechanism of Catalyst Inactivation}

In the purification process of vacuum distillation after the continuous acylation experiment of $\mathrm{TH}$ with excess $\mathrm{AC}$, some findings are worthy of attention. When only $\mathrm{AC}$ and 2-ATH are left in the distillation column, there is still water appearing constantly, which indicates that other reactions are taking place in the distillation column at this time. However, when the pure 2-ATH is distilled under the same conditions, only a very small 
amount of water appears. Therefore, it can be speculated that the carbon deposition may be due to the polymerization of 2-ATH in the presence of AC. The molecular size of this polymer is relatively large, and it is easy to block the pores. This speculation can be verified from both a molecular simulation and an experiment.

\subsection{Molecular Simulation}

In this paper, the experimental results [30] of the $\mathrm{TH}$ acylation reaction are used to judge the accuracy of the calculation results of different basis sets and determine the basis sets. The relevant data are given in Part 1 of the Supporting Information. Finally, based on the density functional theory (DFT), we chose B3LYP/6-31+ $(d, p)$ to proceed with the simulation calculation. In the TH acylation reaction, the error between the calculation result and the experimental value is less than $1 \%$, which can be considered as basically accurate. In addition, it is still feasible and effective to extend this basis set to product polymerization reactions, attributing this to the fact that the molecules involved in $\mathrm{TH}$ acylation and product polymerization have similar structures. Schemes 1 and 2 give the TH acylation reaction and product dimerization.<smiles>CC(=O)C=C(C)OC(C)=O</smiles>

Scheme 1. The reaction of thiophene acylation.

2

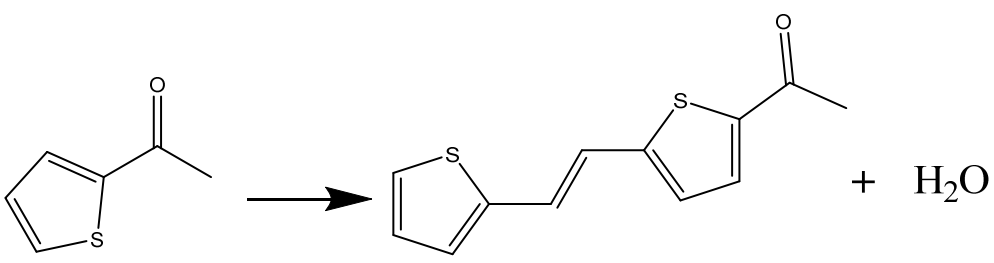

Scheme 2. The reaction of product dimerization.

Schemes 3 and 4 give the result of simulation calculation with or without AC. It can be found that under acidic conditions, the energy barrier for the polymerization of the product 2-ATH to become an intermediate can be greatly reduced (from $335.93 \mathrm{~kJ} / \mathrm{mol}$ to $125.23 \mathrm{~kJ} / \mathrm{mol}$ ), but acidic conditions are necessary for the thiophene acylation. This intermediate can remove a water molecule spontaneously or with the participation of AC to obtain a more stable dimer with a conjugated structure. It can be considered that the presence of AC can greatly reduce the energy barrier (from $287.45 \mathrm{~kJ} / \mathrm{mol}$ to 85.87 $\mathrm{kJ} / \mathrm{mol}$ ) of polymer dehydration and stabilize the unstable intermediate. According to the results of simulation calculations, the presence of $\mathrm{AC}$ can greatly accelerate the product polymerization.

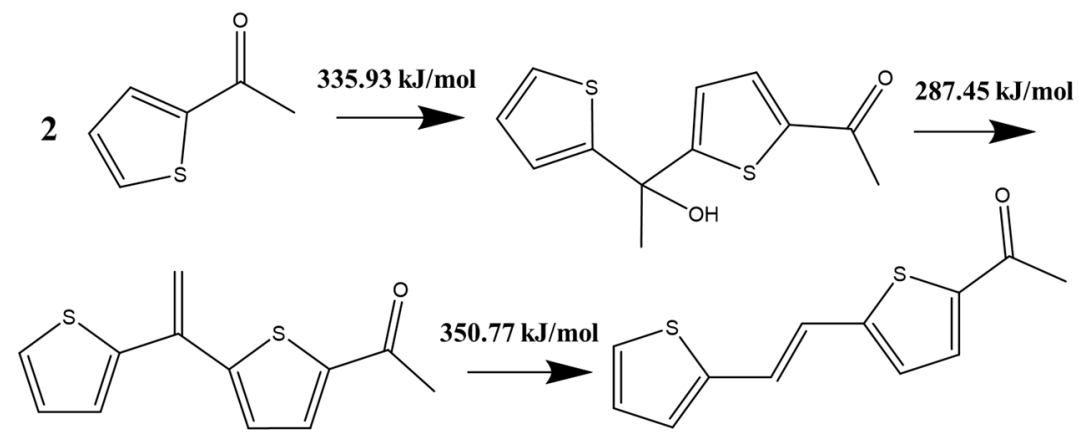

Scheme 3. The mechanism of product dimerization without $\mathrm{H}^{+}$and acetic anhydride (AC). 


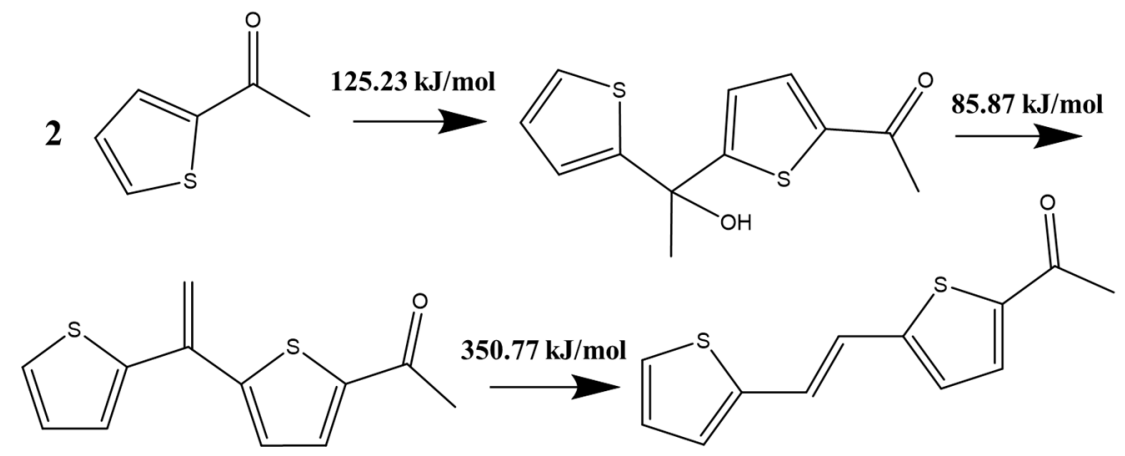

Scheme 4. The mechanism of product dimerization with $\mathrm{H}^{+}$and AC.

\subsection{Soaking Molecular Sieve Inactivation Experiment}

In order to find out the influence of the four components (especially AC) in the system on the production of the polymer and the inactivation of the molecular sieve, and to verify the conclusion of the simulation calculation, the experiment of soaking the molecular sieve is designed. The reaction temperature and time are $80^{\circ} \mathrm{C}$ and $4 \mathrm{~h}$, respectively.

\subsubsection{The Influence of Components on the Inactivation of $\mathrm{H} \beta$ Molecular Sieve}

Since the polymer is formed by 2-ATH, which must be the key component to inactivate the molecular sieve, this means that the soaking liquid must contain 2-ATH. Therefore, this paper chooses four solutions (pure 2-ATH, a mixture of 2-ATH and AC, a mixture of 2-ATH and $\mathrm{TH}$ and a mixture of 2-ATH and $\mathrm{AA}$ ) to soak the $\mathrm{H} \beta$ for the specified time (30 min, $60 \mathrm{~min}, 90 \mathrm{~min}$ and $120 \mathrm{~min}$ ). The dosage of 2-ATH added in the four soaking solutions is $20 \mathrm{~mL}$. The temperature and molar ratio of the soaking solution are, respectively, $80^{\circ} \mathrm{C}$ and 1:1. In addition, the dosage of the molecular sieve soaked in each set of experiments is $1 \mathrm{~g}$.

Figure 1 gives the experiment results. The $\mathrm{H} \beta$ in the mixture of 2-ATH and AC has the most severe inactivation. In this case, soaking for only $30 \mathrm{~min}$, in the subsequent batch reaction, the conversion rate is less than $88 \%$, which shows that the massive coexistence of $\mathrm{AC}$ and 2-ATH in the reaction system can greatly accelerate the inactivation of the molecular sieve. Secondly, pure 2-ATH also has a greater impact compared with the pure TH, AA and $\mathrm{AC}$ on the inactivation. Therefore, it is necessary to avoid the massive coexistence of $\mathrm{AC}$ and 2-ATH as much as possible, and prompt 2-ATH to leave the pores of the catalyst in time.

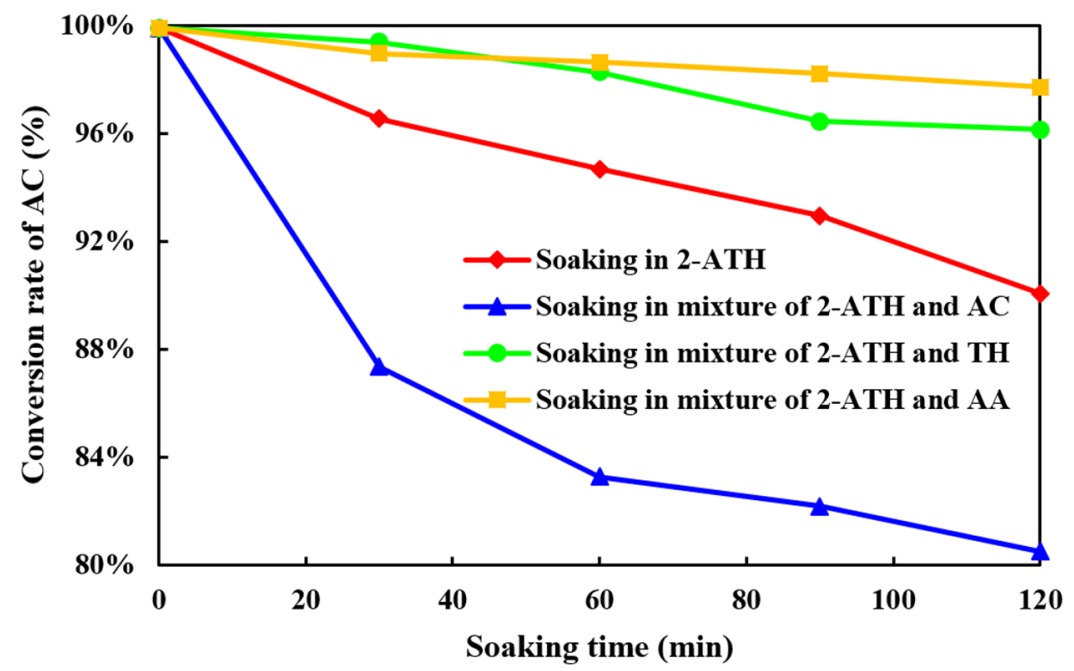

Figure 1. The influence of materials on the inactivation of $\mathrm{H}$-beta $(\mathrm{H} \beta)$ molecular sieve. 


\subsubsection{The Influence of Temperature on the Inactivation of $\mathrm{H} \beta$ Molecular Sieve}

In addition to the composition, the temperature of the reaction has also an important impact on the inactivation. Therefore, another series of soaking experiments are designed to further explore the effect of reaction temperature. The dosage of 2-ATH and $\mathrm{H} \beta$ is $20 \mathrm{~mL}$ and $1 \mathrm{~g}$, respectively. The soaking time and molar ratio are $120 \mathrm{~min}$ and 1:1, respectively. The soaking temperature is $40^{\circ} \mathrm{C}, 50^{\circ} \mathrm{C}, 60^{\circ} \mathrm{C}, 70^{\circ} \mathrm{C}$ and $80^{\circ} \mathrm{C}$, respectively.

Figure 2 shows the experimental results. When the soaking solution is pure 2-ATH, the inactivation and temperature have no relationship. However, when the soaking solution is composed of $\mathrm{AC}$ and 2-ATH, the inactivation and temperature have an obvious positive correlation. The higher the reaction temperature, the more serious the inactivation of the molecular sieve. This situation is not reflected in the soaking solution composed of the 2-ATH and TH and the 2-ATH and AA.

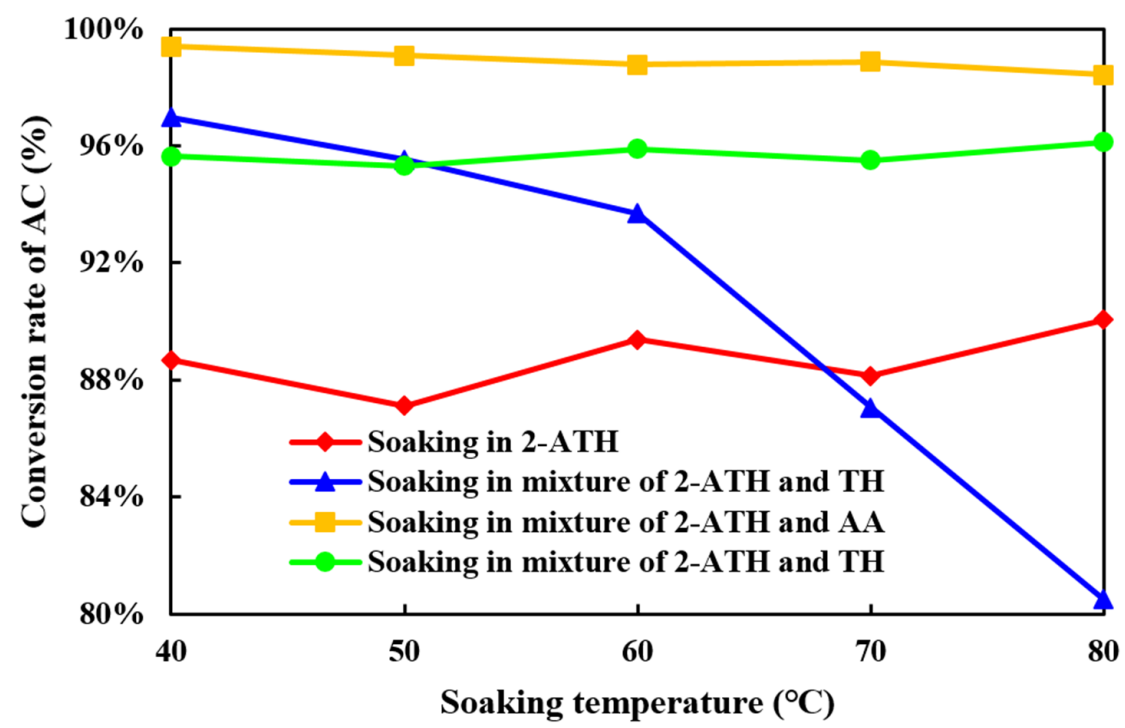

Figure 2. The influence of soaking temperature on the inactivation of $\mathrm{H} \beta$ molecular sieve.

\subsubsection{Discussion}

A key conclusion can be drawn from the above two series of experiments. The massive coexistence of 2-ATH and AC in the system can greatly accelerate the inactivation rate of the molecular sieve attributing to the accelerated formation of polymers, and temperature also has a corresponding effect. The modified dimerization reaction can be shown in Scheme 5 .

2

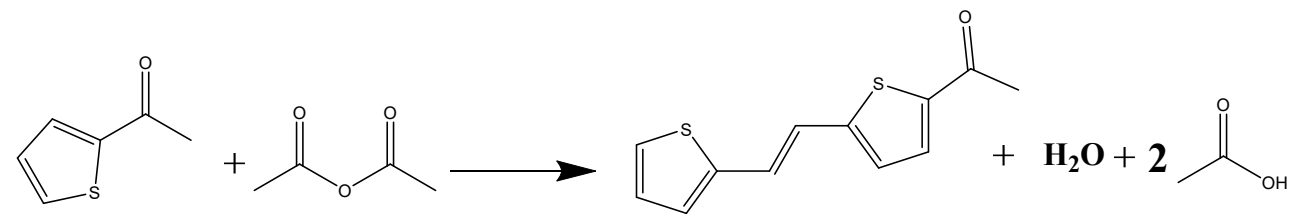

Scheme 5. The reaction of product dimerization with AC.

In the continuous experiments of the thiophene acylation carried out in the previous study [23], the amount of substance of AC was more than that of $\mathrm{TH}$, which is an unreasonable raw material molar ratio and may promote the dimerization and the inactivation rate of the molecular sieve. In addition, in their experiments, the inactivation rate of molecular sieves shows a gradually accelerating trend. Based on the phenomena observed in the distillation process, the possible reaction mechanism given by the molecular simulation and the results of the soaking experiment, it can be confirmed that the presence of excess $\mathrm{AC}$ is a crucial factor leading to the inactivation of the molecular sieve. Therefore, reversing the molar ratio of the $\mathrm{TH}$ and $\mathrm{AC}$ to consume $\mathrm{AC}$ as much as possible and avoid excessive contact between $\mathrm{AC}$ and 2-ATH is a feasible improvement idea for continuous experiments 
of the thiophene acylation reaction. From another perspective, the TH acylation reaction and the 2-ATH polymerization reaction actually have a competitive relationship because they both require the participation of AC. Therefore, a proper amount of TH retained in the system can also inhibit the polymerization reaction.

\section{Improvement of Continuous Thiophene Acylation}

\subsection{Feasibility Verification}

Since the continuous reaction takes a long time, it is first necessary to verify its feasibility when the dosage of TH used is more than that of AC by batch reaction. Detailed verification data are given in Part 2 of the Supporting Information.

\subsection{Continuous Experiment}

3.2.1. The Influence of the Molar Ratio of AC to TH on the Continuous Acylation of Thiophene

The reaction results after the raw material with different molar ratios (TH:AC $=1: 0.4$, 1:0.5 and 1:0.6) is injected into the reactor through the pump are shown in Figure 3. In this section, the total volume flow of reactants with different molar ratios is $0.05 \mathrm{~mL} / \mathrm{min}$. When the molar ratio of raw material is 1:0.4, 1:0.5 and 1:0.6, the residence time is $135 \mathrm{~min}$, $140 \mathrm{~min}$ and $150 \mathrm{~min}$, respectively. The residence time can be defined that the timing starts when the reaction liquid contacts the lower part of the catalyst bed, and stops timing until the reaction liquid completely floods the upper end of the catalyst bed. Under the same volume flowrate $(\mathrm{VF})$, the residence time is different under different molar ratios, which indicates that the difficulty of the internal diffusion of raw material with different molar ratios on the catalyst is different. Furthermore, the greater the content of $\mathrm{TH}$ (in the reaction system and specified raw material molar ratio, the sum of the contents of TH and 2-ATH is constant), the greater the difficulty of internal diffusion. The permeation rate of the raw material from the surface of the molecular sieve to the inside of it is defined as the permeation velocity. When the molar ratio of raw material is $1: 0.4,1: 0.5$ and 1:0.6, the permeation velocity is $0.0144 \mathrm{~mL} / \mathrm{min}, 0.0157 \mathrm{~mL} / \mathrm{min}$ and $0.0180 \mathrm{~mL} / \mathrm{min}$, respectively. Detailed calculation data are given in Part 4 of the Supporting Information. The conclusion is that the more AC content there is, the easier it is for the raw material to permeate into the molecular sieve under the same VF. In addition, this difference in permeation velocity can also reflect the different flow difficulty of the raw material in the pores of the molecular sieve. The more thiophene, the more difficult the flow.

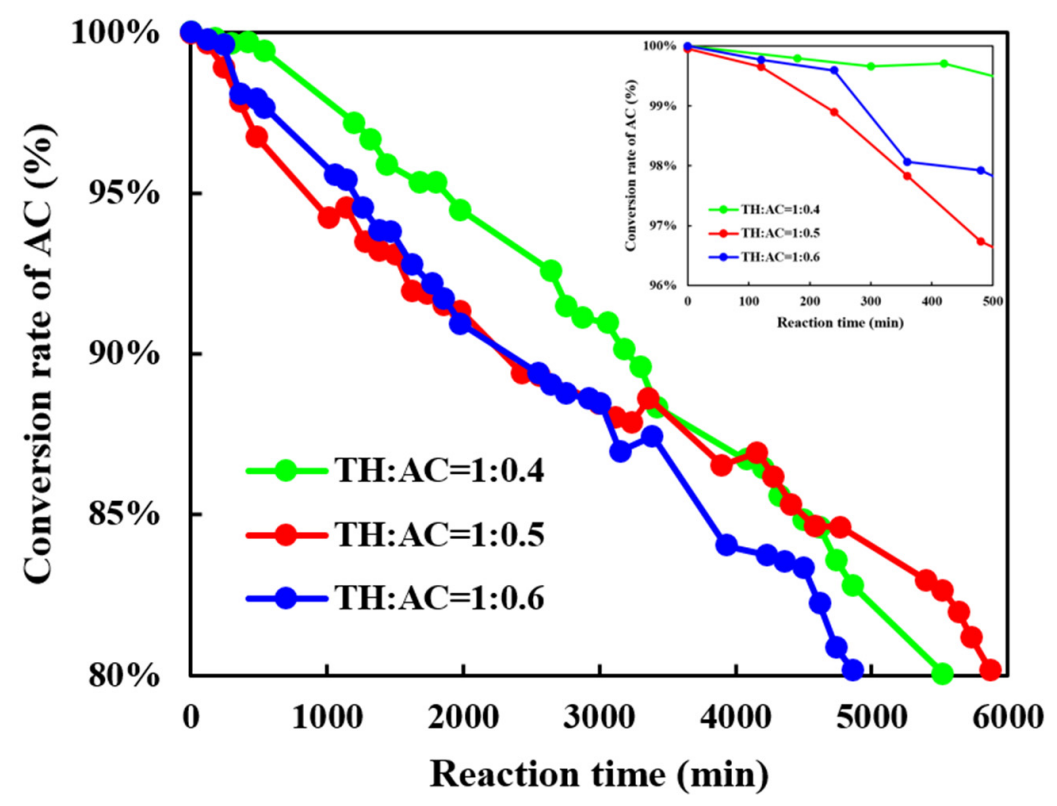

Figure 3. The influence of the molar ratio on the continuous acylation of thiophene. 
The inactivation point of the reaction is specified when the conversion rate of $\mathrm{AC}$ is less than $80 \%$. When the $\mathrm{VF}$ and reaction temperature are $0.05 \mathrm{~mL} / \mathrm{min}$ and $80{ }^{\circ} \mathrm{C}$, respectively, it can be found that in the first $1500 \mathrm{~min}$ at $\mathrm{TH}: \mathrm{AC}=1: 0.6, \mathrm{AC}$ has the highest conversion rate. This means that within a certain concentration range, the higher the initial concentration of $\mathrm{AC}$, the higher the conversion rate in the early stage of the reaction. This phenomenon can be explained by the permeation velocity mentioned above. In the early stage of the reaction, when more AC exists, because the permeation rate is faster, there are more active sites in the pores that actually participate in the reaction, and more AC is consumed. The more the raw material penetrates into the pores of the molecular sieve, the more inner surface that can be contacted, and the more active sites that participate in the reaction. Subsequently, the conversion rates of these processes (TH:AC $=1: 0.6$ and $\mathrm{TH}: \mathrm{AC}=1: 0.5)$ gradually approached. After $3000 \mathrm{~min}$, the conversion rate of the TH:AC $=1: 0.5$ exceeds that of TH:AC $=1: 0.6$. This shows, within a certain range of raw material ratio, that the initial conversion rate is higher when there is more $\mathrm{AC}$ in the raw material; however, the inactivation rate of the molecular sieve is faster due to the production of more 2-ATH (strong polarity) that is easily adsorbed on the pores. In Table 1, the dipole moment of the molecule used in this paper is given by Gaussian calculation. The DMF, DMSO and DI mean N,N-Dimethylformamide, Dimethyl sulfoxide and Dichloroethane, respectively. Comparing $\mathrm{TH}: \mathrm{AC}=1: 0.4$ and $\mathrm{TH}: \mathrm{AC}=1: 0.5$, it can be found that the $\mathrm{AC}$ initial conversion rate of the former is higher than that of the latter, attributing to the lower initial AC concentration of the former. As the reaction progressed, the gap between the two gradually narrowed until it reversed, due to the different difficulty of the raw material flowing in the pores in the two different molar ratios of the raw material. In TH: AC = 1:0.4, which is more difficult to flow, 2-ATH is more easily adsorbed on the pores, resulting in a faster inactivation at this time. Therefore, the best reaction effect can be obtained when the reaction molar ratio is $1: 0.5$, and the productivity of the catalyst is $21.56 \mathrm{~g} / \mathrm{g}$ with a lifetime of $5870 \mathrm{~min}$.

Table 1. The dipole moment calculated value.

\begin{tabular}{ccccccccc}
\hline & 2-ATH & CT & TH & AA & AC & DMF & DMSO & DI \\
\hline Dipole moment & 3.1439 & 0.0000 & 0.5357 & 1.7199 & 4.0654 & 4.2862 & 4.4153 & 2.9972 \\
\hline
\end{tabular}

In addition, for the molar ratio of three raw materials in the experiment, it can be seen from Figure 3 that the inactivation rate of the molecular sieve is basically uniform, which indicates that the inactivation caused by the polymerization reaction is controlled. As mentioned above (Section 3), when AC and 2-ATH massively coexist, the polymerization can be accelerated. As the activity of the molecular sieve decreases, more and more $\mathrm{AC}$ remains in the system, and the remaining $\mathrm{AC}$, in turn, promotes the polymerization reaction to block the pores, and further reduces the activity of the molecular sieve, which is a mutually accelerated process. From this analysis, it can be seen that the inactivation caused by product polymerization must be an increasingly faster process. This phenomenon is consistent with the inactivation rate shown in previous studies [24] when AC is excessive. Therefore, under the reaction conditions, the main factor of molecular sieve inactivation becomes the adsorption of the product on the pores of the molecular sieve.

\subsubsection{The Influence of VF of Raw Material on the Continuous Acylation of Thiophene}

Figure 4 gives the influence of VF on the conversion rate of AC and the catalyst lifetime. Based on that, the amount of catalyst used and the reactor remain unchanged, and the VF has two effects on the reaction system, residence time and flow velocity. As the VF increases, the residence time decreases and the flow rate increases. The longer the residence time, the better the reaction. However, the flow velocity is a more complicated variable. If the flow velocity is too small, it is difficult for the products to fall off the catalyst in time, resulting in the rapid inactivation of the catalyst, and while the flow velocity is too large, it is difficult for the reactants to be adsorbed by the active sites for reaction. The flow velocity 
often has an optimal value. For this study, the VF can be used directly for optimization, while obtaining a more reasonable residence time and flow velocity. The cause of catalyst inactivation is determined through soaking experiments, that is, product polymerization and adsorption. Furthermore, it is proved that the polymerization is effectively controlled. The main factor of catalyst inactivation is only product adsorption. According to Figure 4, the initial conversion rates corresponding to the three VFs of $0.04 \mathrm{~mL} / \mathrm{min}, 0.05 \mathrm{~mL} / \mathrm{min}$ and $0.06 \mathrm{~mL} / \mathrm{min}$ are almost the same, but the inactivation rate is different. The inactivation rate of $\mathrm{VF}=0.04 \mathrm{~mL} / \mathrm{min}$ is greater than that of $\mathrm{VF}=0.06 \mathrm{~mL} / \mathrm{min}$, indicating that the former has a more serious product adsorption, and its impact exceeds the positive effect brought by the increase in residence time. In addition, the residence time (117 $\mathrm{min}$ ) of $\mathrm{VF}=0.06 \mathrm{~mL} / \mathrm{min}$ is not enough to allow the reaction to proceed completely in the initial stage (initial conversion rate is lower than $100 \%$ ). The $\mathrm{VF}=0.05 \mathrm{~mL} / \mathrm{min}$ has the best performance, owing to compromise between the residence time $(140 \mathrm{~min})$ and the flow velocity $(0.0885 \mathrm{~cm} / \mathrm{min})$. The calculation result of flow velocity is given in Part 5 of the Supporting Information. At this condition, the residence time is sufficient for the fresh catalyst to fully catalyze the reaction, and sufficient flow velocity can be maintained for better desorption of the product.

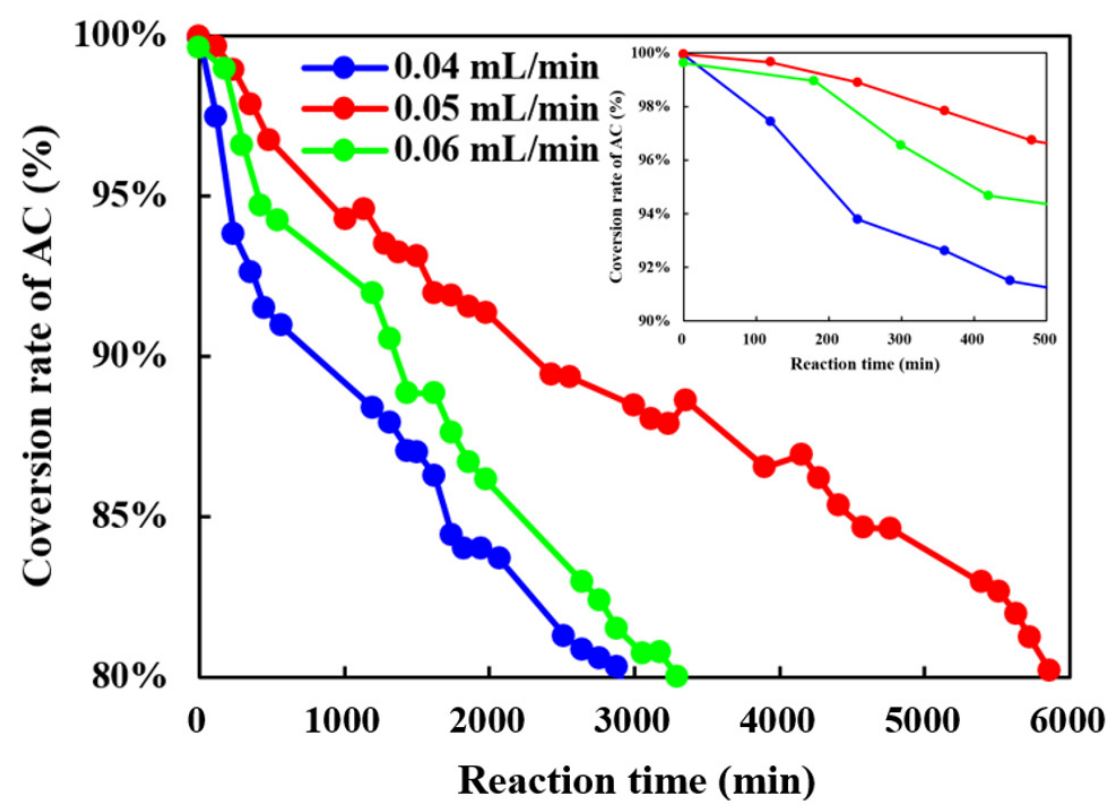

Figure 4. The influence of the volume flowrate (VF) on the continuous acylation of thiophene.

\subsubsection{The Influence of Solvents on the Continuous Acylation of Thiophene}

A suitable solvent can effectively extend the lifetime of the molecular sieve. The solvent must be a small molecule so that it can enter the pores. In addition, the boiling point of the solvent should not be too low to avoid violent boiling in the reaction. For ordinary small molecules, the greater the dipole moment, the greater the polarity, so the polarity can be compared by the dipole moment.

The first solvent to be considered is the by-product AA in the reaction. In a previous study [23], as a solvent, AA achieved a good effect on the extension of the lifetime of the catalyst, which shows that it has a good change in the fluidity in the pores. Based on the TH:AC:AA =1:0.5:0.5, the productivity of the catalyst is $10.04 \mathrm{~g} / \mathrm{g}$ with a lifetime of $3300 \mathrm{~min}$. Experiments on other dosages of AA are also carried out, and relevant experimental results are given in Figure S2 of Part 6 of the Supporting Information. These results indicate that the effect of adding AA is not acceptable. Figure 5 gives the research result. The AA, as a by-product, has a significant inhibitory effect on the reaction, and this effect overwhelms its improvement for the fluidity in the pores under the reaction conditions. Therefore, other solvents need to be found. Considering that the adsorption of polar 2-ATH molecular of 
larger volume on the pores is an important reason for the inactivation of the catalyst, using a polar molecule of smaller volume to pull it from the pores can be considered. Meeting this requirement, molecules with a higher boiling point are N,N-Dimethylformamide (DMF) and Dimethyl sulfoxide (DMSO). According to Table 1, the polarity of DMSO is greater than DMF; therefore, we first use DMF as a solvent for research. When the same amount of DMF as AC is added to the raw material, the initial conversion rate of the $\mathrm{AC}$ is reduced to less than $10 \%$, and the reaction is completely inhibited. This can be attributed to the fact that DMF also has a strong polarity, so that the active site of the reaction is quickly covered and the reaction cannot proceed. Therefore, it is necessary to find a solvent with less polarity. Dichloroethane (DI) can become a new candidate. It should be pointed out that in this experiment, the molar ratio of TH:AC:Solvent is 1:0.5:0.5, and the VF is $0.05 \mathrm{~mL} / \mathrm{min}$. It can be found that the inactivation rate of the molecular sieve is still accelerated when DI is used as a solvent. This can also be attributed to the fact that the DI molecule that still has a certain polarity can quickly adsorb on the pores of the molecular sieve and become a new substance that inactivates molecular sieves. According to the research results of DMF, DI, and AA as solvents, it can be found that the less polar substances can achieve better results. Therefore, the higher polarity DMSO has no considering value at all, while the carbon tetrachloride (CT) with almost no polarity becomes a new candidate. It can obtain a surprising effect. In the experiment of nearly $8000 \mathrm{~min}$, the conversion rate of AC always remains above $98 \%$, which is an important breakthrough for the study of the continuous acylation of thiophene, and the lifetime of the molecular sieve is greatly extended. This amazing effect can also be explained. For one thing, as mentioned above, due to the excess of $\mathrm{TH}$, the inactivation caused by the polymerization reaction is well suppressed. For another, $\mathrm{CT}$ also helps 2-ATH leave the pores, exposing more active sites. In the experiment, we can find that taking analytically pure 2-ATH and CT, the two can be quickly mixed uniformly. In addition, CT can also play a role in diluting the reactants to increase the conversion rate of the AC. Therefore, it can be considered that CT is a better solvent for the thiophene acylation reaction. When the molar ratio of TH:AC:CT is 1:0.5:0.5 and the reaction time is $15,000 \mathrm{~min}$, the productivity of the catalyst can exceed $45 \mathrm{~g}$, far exceeding the previous best results. At this time, the conversion rate of AC is still above $96 \%$, and the reaction can be continued. In addition, the selectivity of 2-ATH can also exceed $99.6 \%$. Table 2 shows the research results of all continuous experiments.

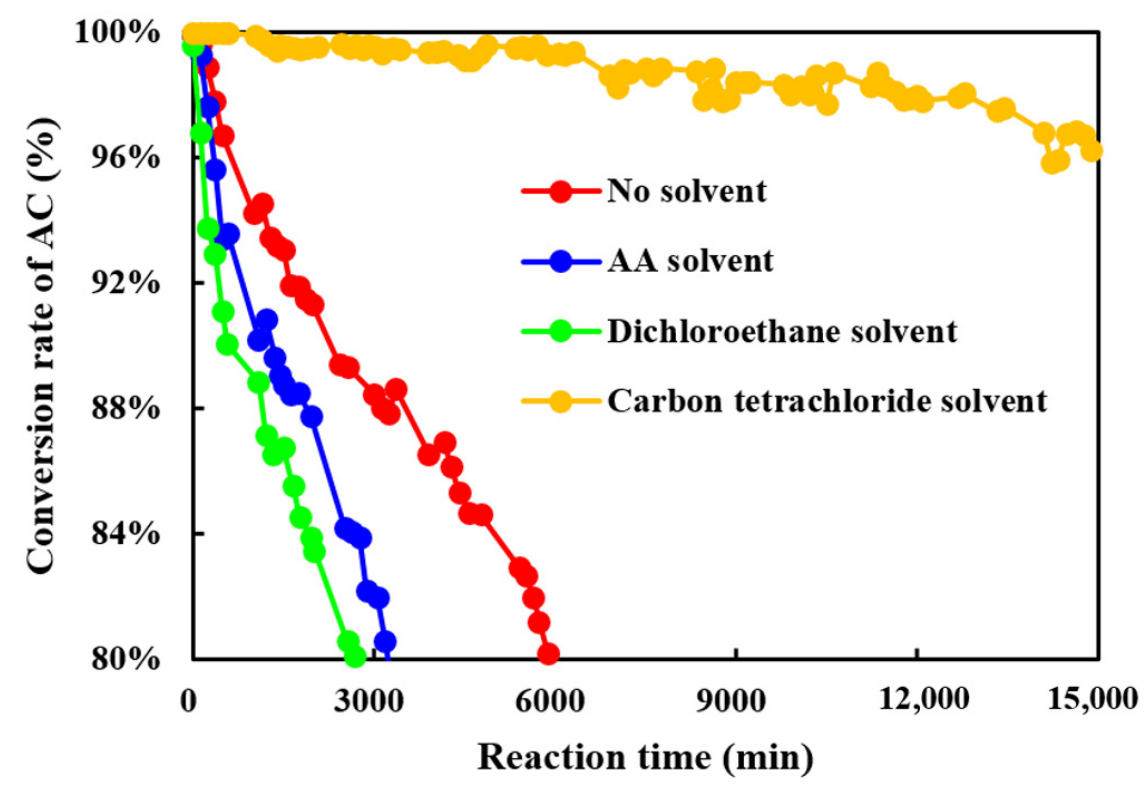

Figure 5. The influence of the solvents on the continuous acylation of thiophene. 
Table 2. The comparisons of results for different continuous processes.

\begin{tabular}{|c|c|c|c|c|c|c|c|}
\hline Number & $\begin{array}{l}\text { Volume } \\
\text { Flowrate } \\
\text { (mL/min) }\end{array}$ & $\begin{array}{c}\text { Catalyst } \\
\text { Dosage (g) }\end{array}$ & $\begin{array}{l}\text { Type of } \\
\text { Solvent }\end{array}$ & $\begin{array}{c}\text { Molar Ratio of } \\
\text { Raw Material } \\
\text { (TH:AC:X) }\end{array}$ & $\begin{array}{c}\text { Initial } \\
\text { Conversion } \\
\text { Rate (\%) }\end{array}$ & $\begin{array}{l}\text { Lifetime } \\
\text { (min) }\end{array}$ & $\begin{array}{l}\text { Production } \\
\text { Capacity of } \\
\text { Catalyst (g) }\end{array}$ \\
\hline 1 & 0.05 & 6.00 & No & 1:0.4:0 & 100.00 & 5520 & 18.07 \\
\hline 2 & 0.05 & 6.00 & No & 1:0.5:0 & 100.00 & 5870 & 21.56 \\
\hline 3 & 0.05 & 6.00 & No & 1:0.6:0 & 100.00 & 4860 & 19.92 \\
\hline 4 & 0.04 & 6.00 & No & 1:0.5:0 & 100.00 & 2880 & 8.55 \\
\hline 5 & 0.06 & 6.00 & No & 1:0.5:0 & 99.67 & 3300 & 15.06 \\
\hline 6 & 0.05 & 6.00 & AA & 1:0.5:0.1 & 99.82 & 2910 & 10.09 \\
\hline 7 & 0.05 & 6.00 & AA & $1: 0.5: 0.3$ & 100.00 & 2850 & 9.38 \\
\hline 8 & 0.05 & 6.00 & AA & 1:0.5:0.5 & 99.94 & 3300 & 10.04 \\
\hline 9 & 0.05 & 6.00 & DI & 1:0.5:0.5 & 99.61 & 2800 & 8.01 \\
\hline 10 & 0.05 & 6.00 & $\mathrm{CT}$ & 1:0.5:0.5 & 100.00 & $\begin{array}{c}\text { More than } \\
15,000\end{array}$ & $\begin{array}{l}\text { More than } \\
\quad 45.00\end{array}$ \\
\hline $\begin{array}{l}\text { Previous } \\
\text { best results }\end{array}$ & 0.05 & 6.00 & AA & $1: 2: 1$ & 99.98 & 4215 & 15.10 \\
\hline
\end{tabular}

\section{Experimental Preparation}

\subsection{Materials}

Thiophene (Analytical Reagent, AR), acetic acid (AR), acetic anhydride (AR) and 2-acetylthiophene (AR) are provided by Jiangtian Chemical (Nantong, China). In addition, the carbon tetrachloride (AR) and dichloroethane (AR) are provided by Kaimate (Tianjin, China). The $\mathrm{H} \beta$ molecular sieve of Cylinder and powder $(\mathrm{Si} / \mathrm{Al} \approx 25)$ is purchased from Nankai University Catalyst limited company (Tianjin, China). The diameter and height of the cylindrical catalyst are about $1-1.5 \mathrm{~mm}$ and $3-6 \mathrm{~mm}$, respectively. The pore volume of the catalyst is $0.48 \mathrm{~cm}^{3} / \mathrm{g}$.

\subsection{Catalyst Pretreatment}

In order to ensure that the template and other impurities remaining in the $\mathrm{H} \beta$ molecular sieve are removed cleanly, the $\mathrm{H} \beta$ needs to be calcined in a muffle furnace before it is used. Firstly, the temperature is raised to $120^{\circ} \mathrm{C}$ at $10{ }^{\circ} \mathrm{C} / \mathrm{min}$, maintained for $2 \mathrm{~h}$, and then raised to $450^{\circ} \mathrm{C}$, thermostated for $5 \mathrm{~h}$, and when it drops freely to below $100{ }^{\circ} \mathrm{C}$, the $\mathrm{H} \beta$ is transferred to a desiccator and cooled to room temperature.

\subsection{Soaking Experiment}

In a 3-neck round-bottom flask fresh, the molecular sieve is immersed in the specified material or the corresponding mixture for a specified period of time at a specified temperature with stirring, and then it cools and stands for $60 \mathrm{~min}$ to sink the molecular sieve. Subsequently, the supernate is removed as much as possible and then the fresh reaction raw material (TH:AC $=1: 2$ ) is added to the flask with nitrogen seal. The conversion rate of AC is detected by chromatography (Agilent 7890A equipped with a flame ionization detector (FID) detector).

\subsection{Continuous Experiment}

Scheme 6 shows the experimental equipment, where the raw material is slowly injected upward from the bottom of the reactor and the lower end of the reactor is sealed to prevent the reaction liquid from leaking. The product leaves the reactor from the top and enters the sample bottle. Hot water is continuously fed into the jacket of the reactor to ensure a constant temperature. In all continuous reactions, the amount of catalyst used is $6 \mathrm{~g}$, and it is piled up into a cylinder with a diameter of $18 \mathrm{~mm}$ and with a height of $85 \mathrm{~mm}$ in the reactor. Considering that there is less residual $\mathrm{AC}$ in the system, the reaction temperature is designated at $80^{\circ} \mathrm{C}$ to achieve higher catalytic activity. The pump used in the experiment 
is the P230II high pressure constant flow pump used in liquid chromatography, and the volume flow can be considered to be basically accurate.

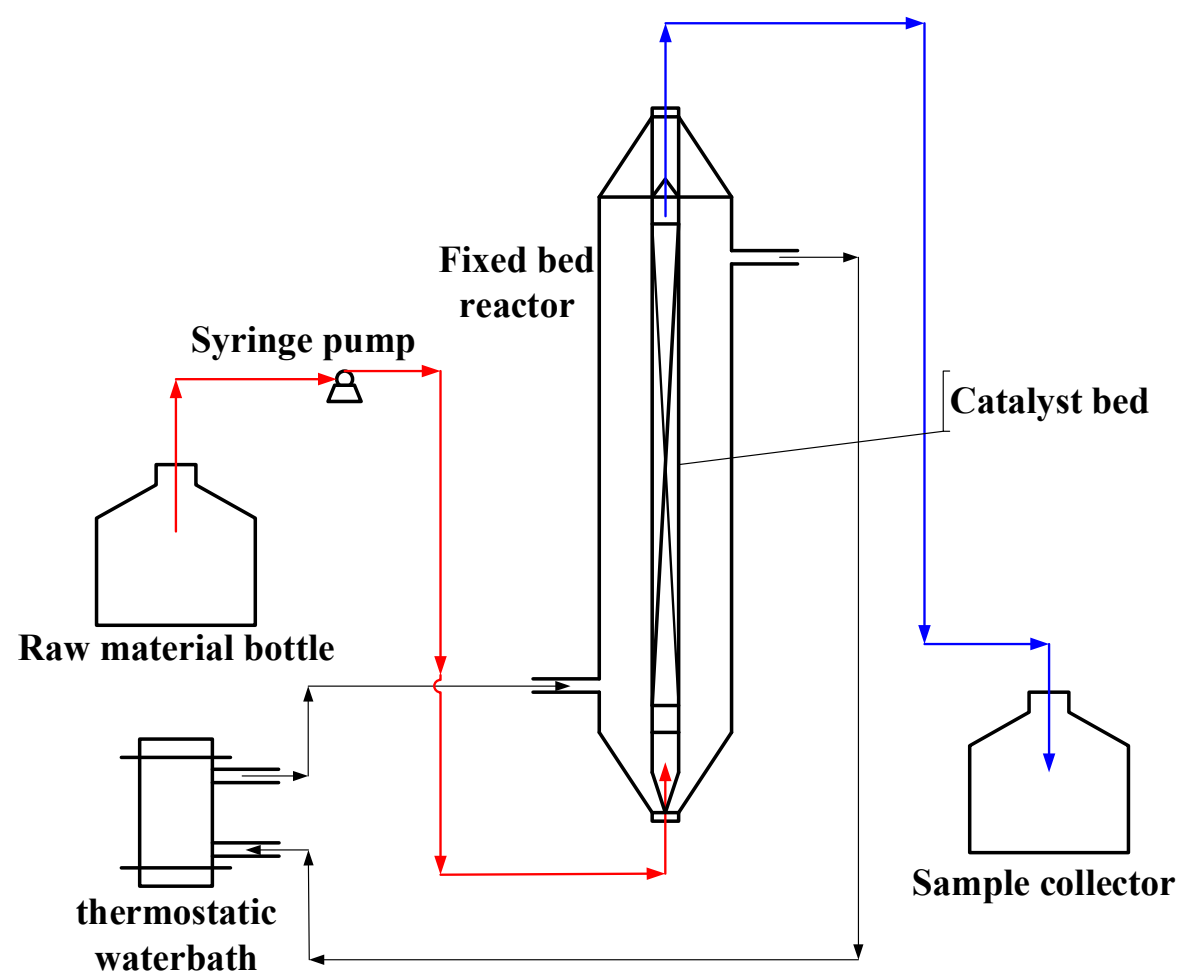

Scheme 6. Schematic diagram of a catalytic unit.

Before the formal experiment, the void ratio of the random packing (cylindrical molecular sieve) should be measured. The void ratio is about $22.19 \%$. Detailed calculation processes are given in Part 3 of the Supporting Information.

\section{Conclusions}

This paper explored the influence of reactants, products and their mixed solutions on the inactivation of the catalyst (molecular sieves) by soaking. In addition, the mechanism of catalyst inactivation was carried out through molecular simulation. It was found that when AC and 2-ATH excessively coexist, the inactivation rate of the catalyst was particularly fast. Furthermore, the polarity of the 2-ATH leading its absorption in the pores of the catalyst to block the active sites was also an important reason for the inactivation. Subsequently, the continuous acylation experiment with excess thiophene was proposed to avoid the abundant coexistence of 2-ATH and AC. In the continuous experiment, the fixed bed reactor was used to optimize the VF and molar ratio of the raw material with the values of 1:0.5 and $0.05 \mathrm{~mL} / \mathrm{min}$, respectively, and this could obtain the productivity of catalyst of $21.56 \mathrm{~g} / \mathrm{g}$. In order to further improve the productivity of the catalyst, the addition of an appropriate solvent to the raw material was studied. Prior to this, the dipole moment of some molecules was calculated through molecular simulations to compare their polarities. In the study, it was found that $\mathrm{CT}$ was used as a solvent and achieved excellent results when added to the reaction raw material. When the molar ratio of TH, AC and CT was 1:0.5:0.5 with equal VF $(0.05 \mathrm{~mL} / \mathrm{min})$ as before, the lifetime and the productivity of the catalyst could exceed 15,000 $\mathrm{min}$ and $45 \mathrm{~g} / \mathrm{g}$, respectively. Furthermore, at this time, the conversion rate of AC was still above $96 \%$. Compared with the best process previously studied, the productivity of the catalyst was increased by at least three times. 
Supplementary Materials: The following are available online at https:/ /www.mdpi.com/2073-434 4/11/3/298/s1, Part 1. Molecular simulation (Table S1. Calculation results, Table S2. Experimental data); Part 2. Batch experiment (Figure S1. The results of the intermittent experiment); Part 3. Calculation of void ratio; Part 4. Qualitative comparison of the difficulty of internal diffusion with different molar ratios (Table S3. Comparison of penetration velocity); Part 5. Calculation of apparent flow velocity; Part 6 . The effect of different AA dosages on the reaction (Figure S2. The influence of the AA in the continuous acylation of thiophene).

Author Contributions: Data curation, S.Y.; Formal analysis, S.Y.; Investigation, S.Y.; Project administration, A.Z.; Supervision, A.Z. All authors have read and agreed to the published version of the manuscript.

Funding: This research received no external funding.

Conflicts of Interest: The authors declare no conflict of interest.

\section{References}

1. Bejblova, M.; Prochazkova, D.; Cejka, J. Acylation Reactions over Zeolites and Mesoporous Catalysts. Chem. Sustain. Chem. 2009, 2, 486-499. [CrossRef]

2. Melero, J.A.; Grieken, R.V.; Morales, G.; Nuno, V. Friedel Crafts acylation of aromatic compounds over arenesulfonic containing mesostructured SBA-15 materials. Catal. Commun. 2004, 5, 131. [CrossRef]

3. Komoto, I.; Matsuo, J.I.; Kobayashi, S. Catalytic Friedel-Crafts Acylation of Heteroaromatics. Top. Catal. 2002, 19, 43. [CrossRef]

4. Heinichen, H.K.; Holderich, W.F. Acylation of 2-Methoxynaphthalene in the Presence of Modified Zeolite HBEA. J. Catal. 1999, 185, 408-414. [CrossRef]

5. Moreau, P.; Finiels, A.; Meric, P.; Fajula, F. Acetylation of 2-methoxynaphthalene in the presence of beta zeolites: Influence of reaction conditions and textural properties of the catalysts. Catal. Lett. 2003, 85, 199-203. [CrossRef]

6. Fromentin, E.; Coustard, J.M.; Guisnet, M.; Mol, J. Acetylation of 2-methoxynaphthalene with acetic anhydride over a HBEA zeolite. Catal. A Chem. 2000, 159, 377-388. [CrossRef]

7. Sartori, G.; Maggi, R. Update 1 of: Use of Solid Catalysts in Friedel-Crafts Acylation, Reactions. Chem. Rev. 2011, 111, 181-214. [CrossRef] [PubMed]

8. Corma, A.; Garcia, H. Lewis acids: From conventional homogeneous to green homogeneous and heterogeneous catalysis. Chem. Rev. 2003, 103, 4307-4365. [CrossRef]

9. Corma, A.; Garcia, H. Lewis acids as catalysts in oxidation reactions: From homogeneous to heterogeneous systems. Chem. Rev. 2002, 102, 3837-3892. [CrossRef] [PubMed]

10. Ullah, L.; Zhao, G.; Xu, Z.; Usman, M.; Zhang, S. 12-Tungstophosphoric acid niched in Zr-based metal-organic framework: A stable and efficient catalyst for Friedel-Crafts acylation. Sci. China Chem. 2018, 4, 1-10. [CrossRef]

11. Ammar, M.; Jiang, S.; Ji, S. Heteropoly acid encapsulated into zeolite imidazolate framework (ZIF-67) cage as an efficient heterogeneous catalyst for Friedel-Crafts acylation. J. Solid State Chem. 2016, 233, 303-310. [CrossRef]

12. Endud, S.; Basir, N.M.; Lintang, H.O. Friedel-Crafts acylationof anisole over heteropoly acid supported on porous montmorillonite. Mater. Sci. Forum 2016, 846, 712-716. [CrossRef]

13. Yuan, B.; Li, Z.S.; Liu, Y.J.; Zhang, S.S. Liquid phase acylation of 2-methylnaphthalene catalyzed by H-beta zeolite. J. Mol. Catal. A Chem. 2008, 280, 210. [CrossRef]

14. Hu, T.; Qin, Z.; Wang, J. Acylation of toluene with acetic anhydride over H beta zeolite. J. Fuel Chem. Technol. $2003,31,624-627$.

15. Kumari, V.D.; Saroja, G.; Ratnamala, A. Vapor phase acylation of phenol over $\mathrm{H}$ beta, $\mathrm{CeH}$ beta and $\mathrm{SO}_{4}{ }^{2-} / \mathrm{ZrO}_{2}$. React. Kinet. Catal. Lett. 2003, 79, 43-51. [CrossRef]

16. Ji, X.; Qin, Z.; Dong, M. Friedel-Crafts acylation of anisole and toluene with acetic anhydride over nano-sized beta zeolites. Catal. Lett. 2007, 117, 171-176. [CrossRef]

17. Ji, X.; Qin, Z.; Dong, M. Acylation of anisole with acetic anhydride over Hbeta/MCM-41 composite molecular sieves. J. Fuel Chem. Technol. 2008, 36, 621-624.

18. Bai, G.; Dou, H.; Fan, X. Synthesis of p-Methoxyacetophenone Catalyzed by Phosphoric Acid Modified Hbeta Zeolite. Fine Chem. 2009, 26, 1992-1995.

19. Li, G.; Li, H.; Zhao, H. Acylation between anisole and acetic anhydride catalyzed by hierarchical porous Hbeta molecular sieve. Mod. Chem. Ind. 2019, 39, 112-116.

20. Tong, T.; Zeng, A. Friedel-Crafts Acylation Reaction of Liquid Thiophene Catalyzed by C25. J. Chem. Eng. Chin. Univ. 2012, 26, 989-993.

21. Ji, C.; Xie, T.; Wu, J. Study on the synthesis of antidepression drug duloxetine hydrochloride and its impurity of intermediates. Chin. J. Synth. Chem. 2018, 26, 6.

22. Fan, S.; Mi, C.; He, X. Synthesis of a novel sedative-hypnotic indiplon. Chin. J. Med. Chem. 2006, 16, 6.

23. Feng, Y.; Zeng, A. Continuous synthesis of 2-acetyl thiophene with C25 zeolite molecular sieve. Chem. Ind. Eng. Prog. 2014, 33, 10. 
24. Chen, Z.; Feng, Y.; Tong, T.; Zeng, A. Effects of acid-modified HBEA zeolites on thiophene acylation and the origin of deac-tivation of zeolites. Appl. Catal. A Gen. 2014, 482, 92-98. [CrossRef]

25. Srivastava, R.; Iwasa, N.; Fujita, S.I.; Arai, M. Dealumination of zeolite beta catalyst under controlled conditions for enhancing its activity in acylation and esterification. Catal. Lett. 2009, 130, 655-663. [CrossRef]

26. Xiong, Y.N.; Chen, W.Q.; Ma, J.J.; Chen, Z.H.; Zeng, A.W. Methods to delay deactivation of zeolites on furannacylation: Continuous liquid-phase technology and solvent effects. Rsc. Adv. 2015, 5, 103695. [CrossRef]

27. Xiong, Y.N.; Chen, W.Q.; Zeng, A.W. Optimization for catalytic performances of $\mathrm{H} \beta$ zeolite in the acylation of 2-methylfuran by surface modification and solvents effect. Res. Chem. Intermed. 2017, 43, 1557-1574. [CrossRef]

28. Leach, A.R. Molecular Modelling Principles and Applications; World Book Publishing House: Beijing, China, 2001.

29. Cao, J.S.; Ren, Q.; Chen, F.W.; Lu, T. Comparative study on the methods for predicting the reactive site of nucleophilic reaction. Sci. China Chem. 2015, 58, 1845-1852. [CrossRef]

30. Roux, M.V.; Temprado, M.; Jime'nez, P.; Notario, R.; Chickos, J.S.; Santos, A.F.L.O.M.; da Silva, M.A.V.R. Thermochemis-try of 2-and 3-acetylthiophenes: Calorimetric and computational study. J. Phys. Chem. A 2007, 111, 11084-11092. [CrossRef] [PubMed] 